\title{
Morphological and in situ local refractive index change induced tuning of the optical properties of titania coated porous gold nanoparticles
}

Cite as: J. Appl. Phys. 128, 054303 (2020); https://doi.org/10.1063/5.0010460

Submitted: 10 April 2020 . Accepted: 17 July 2020 . Published Online: 04 August 2020

Laura Juhász (D), Bence Parditka, Shenouda Shanda Shenouda, Misumi Kadoi, Kei-ichi Fukunaga, Zoltán Erdélyi, and Csaba Cserháti (iD)

Exps:Mark

\section{Lock-in Amplifiers up to $600 \mathrm{MHz}$}
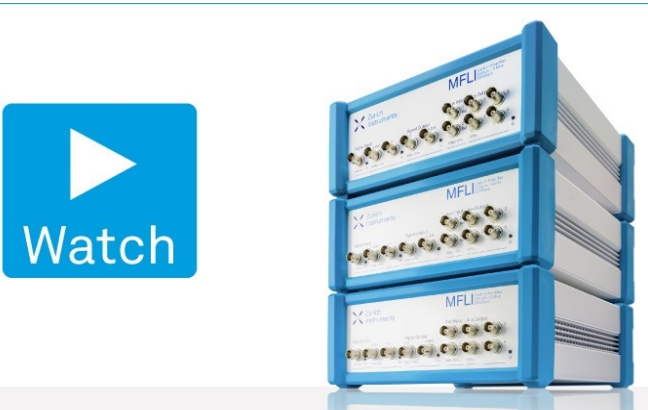


\title{
Morphological and in situ local refractive index change induced tuning of the optical properties of titania coated porous gold nanoparticles
}

Cite as: J. Appl. Phys. 128, 054303 (2020); doi: 10.1063/5.0010460

Submitted: 10 April 2020 - Accepted: 17 July 2020 .

Published Online: 4 August 2020

Laura Juhász, ${ }^{1,2}$ (D) Bence Parditka, ${ }^{7}$ Shenouda Shanda Shenouda, ${ }^{3}$ Misumi Kadoi, ${ }^{4}$ Kei-ichi Fukunaga, ${ }^{5}$ Zoltán Erdélyi, ${ }^{1}$ and Csaba Cserháti ${ }^{1, a)}$ (iD

\author{
AFFILIATIONS \\ ${ }^{1}$ Department of Solid State Physics, Faculty of Sciences and Technology, University of Debrecen, P.O. Box 400, \\ H-4002 Debrecen, Hungary \\ ${ }^{2}$ Doctoral School of Physics, University of Debrecen, Egyetem sqr. 1, 4032 Debrecen, Hungary \\ ${ }^{3}$ Department of Physics, Faculty of Education, Ain Shams University, Roxy, 11341 Cairo, Egypt \\ ${ }^{4}$ IB Group, Department of EP Application, EP Business Unit, JEOL Ltd., 196-8558 Tokyo, Japan \\ ${ }^{5}$ Department of EM Application, EM Business Unit, JEOL Ltd., 196-8558 Tokyo, Japan
}

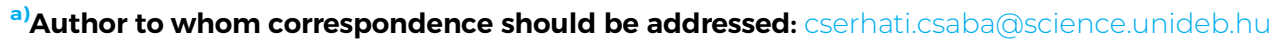

\begin{abstract}
Porous nanoparticles are very popular because of their high surface/volume ratio; moreover, they have stronger plasmonic properties than their solid counterparts. Due to these properties, these are potential candidates in optical, or even in ophthalmological applications. We prepared porous gold nanoparticles on $\mathrm{SiO}_{2} / \mathrm{Si}$ as well as on sapphire substrates with solid-state dewetting-dealloying methods. In this work, we studied the morphological and optical properties of porous gold nanoparticles coated with a thin $(\sim 7 \mathrm{~nm}) \mathrm{TiO}_{2}$ layer using the plasmaenhanced atomic layer deposition method. We show that heat treatments can be used to tune the optical properties of titania coated porous gold hybrid nanoparticles in a wide range of wavelengths. The change in the optical properties is induced by the $\mathrm{TiO}_{2}$ phase transformation, which also initiates a change in the local refractive index, and assisted by the decrease of the melting point of Au on the nanoscale.
\end{abstract}

Published under license by AIP Publishing. https://doi.org/10.1063/5.0010460

\section{INTRODUCTION}

Porous materials in the nanometer-sized range are interesting materials in many fields of science and technology. They are promising candidates for different applications such as recoverable catalysis, drug delivery, photonic devices, nano-chemical reactors, or even in ophthalmology. ${ }^{1-8}$ The synthesis and the formation of hollow nanostructures (nanospheres, nanotubes) in most cases are based on solid-state diffusion and/or reaction between two parent materials; in some cases, the Kirkendall effect has been applied to explain the formation of holes. ${ }^{3,9-11}$ Nanoporous gold nanoparticles with controlled particle and pore size, on the other hand, can be fabricated using a combination of solid-state dewetting and a subsequent dealloying process. ${ }^{12}$ These porous gold nanoparticles (PGNs) have a remarkable three-dimensional structure with a high surface to volume ratio but lose their porous morphology at relatively low temperatures. To prevent the structure from ligament coarsening, a thin $(\sim 5 \mathrm{~nm}) \mathrm{Al}_{2} \mathrm{O}_{3}$ layer can be deposited onto the PGNs with the ALD (atomic layer deposition) method. As was shown, ${ }^{13,14}$ the morphology of the alumina coated porous gold nanoparticles (APGNs) did not change at low temperatures $\left(350-500^{\circ} \mathrm{C}\right)$ but slow out-diffusion of gold started from under the alumina layer at $\sim 600^{\circ} \mathrm{C}$. Close to $\sim 900^{\circ} \mathrm{C}$, faceted gold nanoparticles formed on the surface of the empty alumina shell due to the fast out-diffusion of gold.

If a bulk metal is divided into very small elements, its optical response changes drastically due to the confinement of electrons. If the size of such an object is much smaller than the wavelength of the illuminating light, all the conducting electrons will feel the same homogeneous electromagnetic field and oscillate collectively as a giant dipole, quadrupole, etc. If the applied wave frequency is equal to the 
eigenfrequency of the movement of the electron gas relative to the ionic nuclei, this excitation is resonant, which is called surface plasmon resonance (SPR). ${ }^{15}$ In a more realistic quantum mechanical picture, this corresponds to the excitation of coherent electronic transitions within the conduction band. Strong electromagnetic fields allow for a significant enhancement of weak third-order nonlinear processes, which depend superlinearly on the local field. Metal divided into nanometric elements can give several orders of magnitude greater nonlinear response than its bulk phase. This is a direct consequence of the dielectric confinement and the amplification depends significantly on the dielectric contrast between the nanometric elements and the host medium. For these reasons, metal nanoparticles are ideal SPR structures, as their size can be positioned in the desired range. Surface plasmons, on the other hand, undergo a decay on the femtosecond timescale, both by radiative damping and via the formation of "hot" charge carriers, ${ }^{16}$ which then relax by heating the nanostructure and its surroundings. Plasmonic losses cannot be completely eliminated but can be reduced by proper choice of the nanostructure geometry. In the case of a single nanoparticle, for instance, absorption losses are reduced. Porous metal nanoparticles are even more promising as pore-ligaments further subdivide the nanostructure. The wavelength at which localized surface plasmon resonances (LSPR) occur depends on the local dielectric environment, the size, shape, and the geometry of the PGNs. ${ }^{17-20}$ The dielectric surroundings of the metal can be varied, e.g., coating with metal-oxide, which not only affects the SPR properties but can also have a beneficial effect on the thermal stability of the particles. In particular, hybrid nanostructures that separate light trapping and SP-excitation sites offer significant advantages. Hybrid integration extends the use of conventional plasmonic materials such as noble metals into the IR spectral domain, which is otherwise not easily accessible. ${ }^{21}$

In centrosymmetric media (such as noble metal nanoparticles), the even-ordered nonlinearities from the electric dipole origin disappear. The first non-zero nonlinear sensitivity is then the thirdorder one. However, at the interface between two centrosymmetric media, the inversion symmetry is naturally broken, and secondorder effects are allowed. ${ }^{22,23}$ The determination of the surface $\chi^{(2)}$ tensor elements provides information about the atomic structure of the interface, the concentration, and the orientation of adsorbed molecules, etc., and, hence, vice versa, the interface determines the nonlinear plasmonic properties. ${ }^{24}$ For example, in a recent study, ${ }^{25}$ hybrid $\mathrm{Au}-\mathrm{TiO}_{2}$ platforms for second-order nonlinear plasmonic applications have been prepared, which rely on charge transfer at the interface of $\mathrm{Au}$ with $\mathrm{TiO}_{2}$; and achieving a clean/controllable interface is a key factor. This study also shows that there is a recent surge of interest in hybrid $\mathrm{Au}-\mathrm{TiO}_{2}$ platforms for nonlinear plasmonic applications too. Experimental results on enhancing the second harmonic generation (SHG) due to SPR in noble metal particles also exist if the particles are not spherical, ${ }^{26,27}$ or if the spherical particles are scattered on the surface between two different media, thus breaking the inversion symmetry, ${ }^{28}$ or if the low symmetry aggregates, or even in a centrosymmetric position through the excitement of the contribution of the electric quadrupole. ${ }^{29}$ Thus, noble nanoparticles with a dielectric coating, such as $\mathrm{Au}-\mathrm{TiO}_{2}$ hybrid nanoparticles, can offer excellent opportunities for plasmonic, nonlinear plasmonic applications. However, knowing and controlling its structure is a key issue.
This work shows the way of designing and tuning the structure, as well as basic plasmonic properties of hybrid titania coated porous gold nanoparticles (TPGNs). We show that in comparison with APGNs, pure heat treatment of TPGNs can be used to tune their optical properties in a wide range of wavelengths. The change in the optical properties is induced by the phase transformation of the $\mathrm{TiO}_{2}$ and assisted by the decreasing melting point of $\mathrm{Au}$ on the nanoscale.

\section{MATERIALS AND METHODS}

\section{A. Sample preparation}

Porous gold nanoparticles were fabricated on $\mathrm{SiO}_{2}$ as well as on sapphire (CrysTec GmbH, Berlin, c-plane (0001)) substrates from laminated thin gold and silver layers $(6 \mathrm{~nm} \mathrm{Au} / 16 \mathrm{~nm} \mathrm{Ag})$, which were deposited on the flat surface of the substrates by magnetron sputtering. $\mathrm{SiO}_{2}$ substrates were prepared by growing a few hundred nanometers of $\mathrm{SiO}_{2}$ on the surface of pure $\mathrm{Si}$. Sapphire substrates were used for optical investigations.

$\mathrm{Au}-\mathrm{Ag}$ alloy nanoparticles $(\sim 330 \mathrm{~nm}$ average diameter $)$ were fabricated by solid-state dewetting technique, i.e., annealing the samples at $850^{\circ} \mathrm{C}$ in a dynamic $\mathrm{Ar}+\mathrm{H}_{2}$ atmosphere for $30 \mathrm{~min}$. The silver was then selectively etched from the alloy nanoparticles rinsing them in $65 \mathrm{wt}$ \% nitric acid for $15 \mathrm{~min}$ at room temperature. $^{12}$ As a result, porous gold nanoparticles formed with an average pore size of $\sim 10-20 \mathrm{~nm}$. We would like to emphasize that the diameter of the PGNs and the pore size is mainly determined by the total thickness of deposited gold and silver layers.

A Beneq-TFS 200 ALD reactor was used to coat the PGNs with a $7 \mathrm{~nm}$ thick $\mathrm{TiO}_{2}$ layer by plasma-enhanced atomic layer deposition (PE-ALD). The precursor materials were $\mathrm{TiCl}_{4}$ and oxygen plasma. The layers were prepared at $45^{\circ} \mathrm{C}$. The pressure in the chamber and in the reactor was $7.23 \mathrm{mbar}$ and $1.186 \mathrm{mbar}$, respectively. The pulse time for $\mathrm{TiCl}_{4}$ was $0.6 \mathrm{~s}$, which was followed by a $3.5 \mathrm{~s}$ nitrogen purge and a $10 \mathrm{~s}$ oxygen plasma at $50 \mathrm{~W}$ power. The cycle ended with a $3.5 \mathrm{~s}$ nitrogen purge. The growth rate was $0.7 \AA$ Acycle. Accordingly, 100 cycles were applied to build the $7 \mathrm{~nm}$ thick $\mathrm{TiO}_{2}$ coating. Because the PE-ALD method was used, the coating was produced at such a low temperature where the ligament coarsening is suppressed.

To study the morphological evolution of the PGNs, a series of samples were annealed at $350^{\circ} \mathrm{C}, 600^{\circ} \mathrm{C}, 700^{\circ} \mathrm{C}, 800^{\circ} \mathrm{C}$, and $900^{\circ} \mathrm{C}$ for 30 and $60 \mathrm{~min}$ in an ambient atmosphere. The $60 \mathrm{~min}$ heat treatments were realized as two consecutive $30 \mathrm{~min}$ ones.

\section{B. Sample characterization}

The morphology of the PGNs was studied by scanning electron microscope (SEM, HITACHI-S4300-CFE and Thermo Fisher Scientific-Scios 2). Low accelerating voltage $(5 \mathrm{kV} \& 2 \mathrm{kV})$ and small working distance $(\leq 5 \mathrm{~mm})$ were used for high resolution and good surface sensitivity. NI Vision software was applied on the secondary electron (SE) images to measure the morphological features of the nanoparticles.

Optical extinction spectra were measured by a SHIMADZU 3600 UV-VIS spectrophotometer in the spectral range of 300-2000 nm. 
Cross cut and lamellas of the nanoparticles for transmission electron microscopy were prepared by a JEOL JIM-4700F focused ion beam (FIB) apparatus and investigated by JEOL-JEM-2800 and JEOL 2000-FXII transmission electron microscopes (TEMs) equipped with an energy dispersive spectrometer (EDS).

\section{RESULTS}

\section{A. Morphology of the titania-porous gold hybrid nanoparticles}

According to SEM studies, the morphology does not change up to $600^{\circ} \mathrm{C}$, and the structure of the nanoparticles (i.e., diameter, pore and ligament size, porosity, etc.) is the same as after coating. As an example, Fig. 1(a) shows a bright-field TEM image (BFI) of the cross section of a titania coated porous gold nanoparticle
(TPGN) annealed at $350^{\circ} \mathrm{C}$ for $1 \mathrm{~h}$. The figure shows the inner structure of the particle. Figures 1(b) and 1(c) display the $\mathrm{x}$-ray elemental distribution map of gold and titanium in the same particle, respectively. These images show that the PE-ALD method evenly covers the entire surface of the particle with $\mathrm{TiO}_{2}$, even inside the pores.

In Fig. 1(d), the overlaid $\mathrm{Ti}$ and $\mathrm{Au}$ maps show how uniform the $\mathrm{TiO}_{2}$ layer is. Note that the titania also covers the substrate. The image also proves that titania preserves the morphology of the PGN after annealing at this low temperature.

Increasing the annealing temperature above $600^{\circ} \mathrm{C}$, dark and light regions appear on the surface of the nanoparticles due to the slow diffusion of gold. Note that the porous surface pattern is still visible [see Fig. 2(a)]. However, annealing the specimen at $750{ }^{\circ} \mathrm{C}$ for an hour, the morphology completely disappears. As shown in
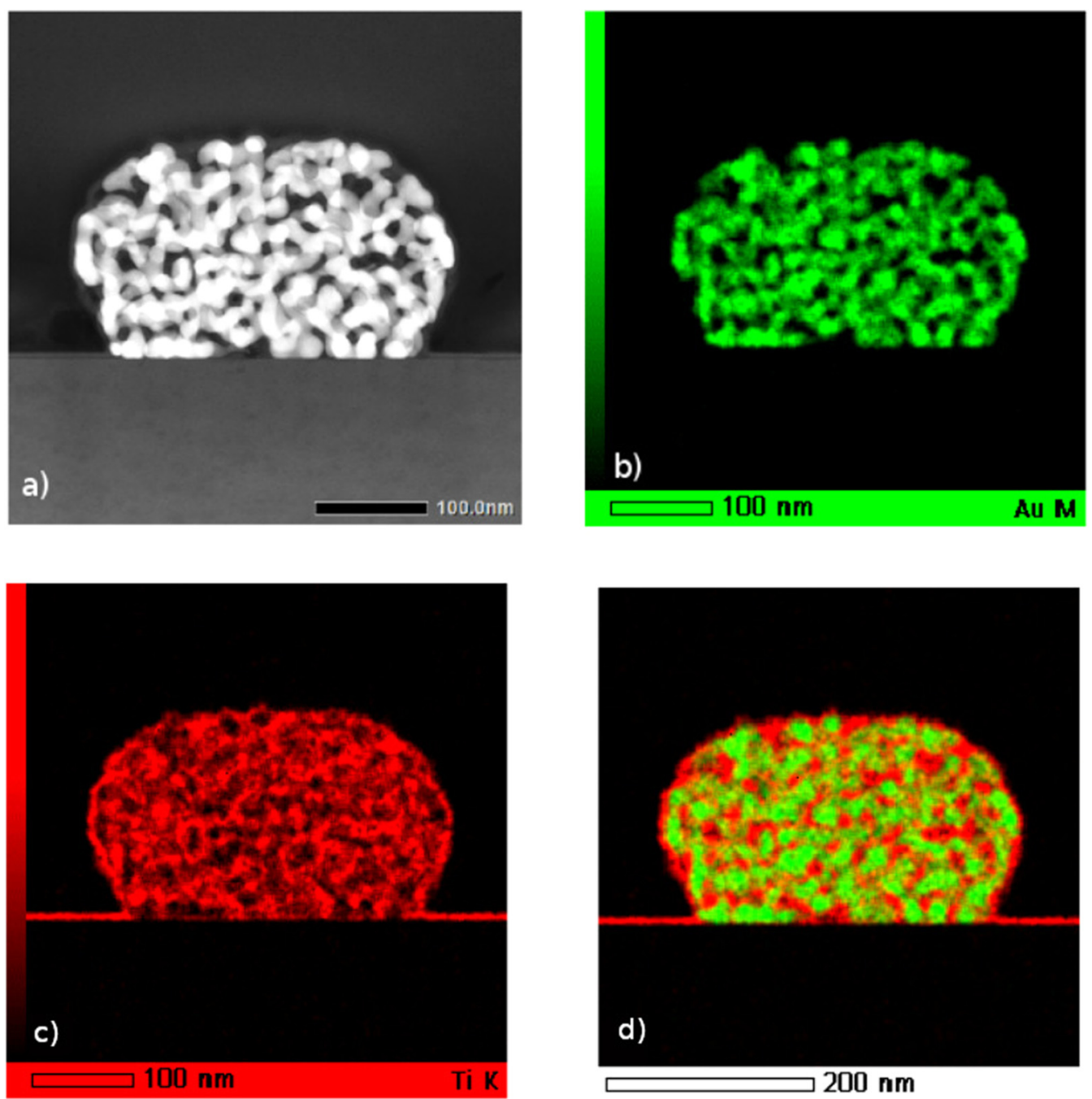

$200 \mathrm{~nm}$

FIG. 1. TPGNs annealed at $350^{\circ} \mathrm{C}$ for $1 \mathrm{~h}$. Cross section was prepared by FIB and imaged by TEM/EDS. (a) Cross section view of TPGN, (b) Au elemental distribution, (c) Ti elemental distribution, and (d) Au and Ti distribution. 


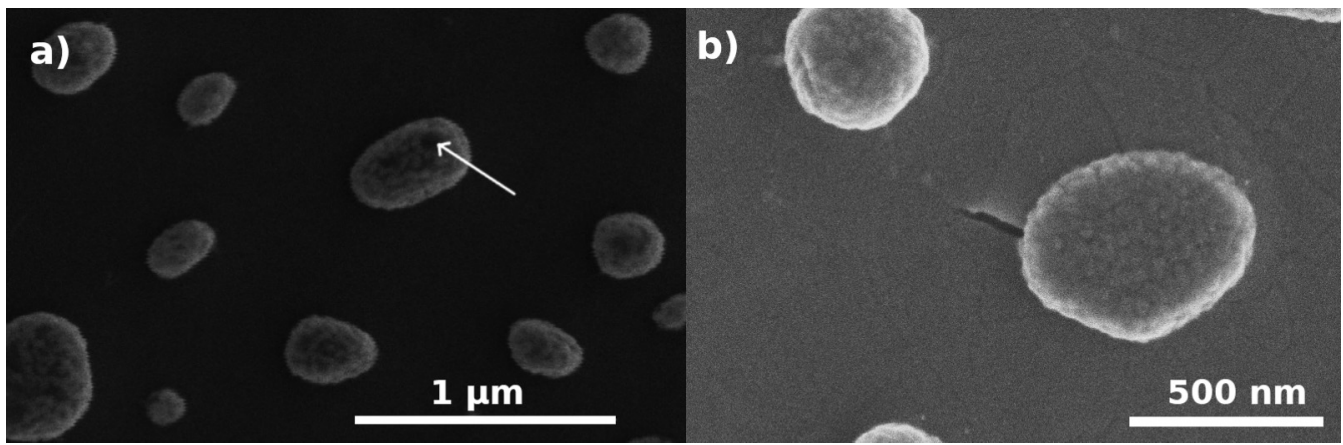

FIG. 2. (a) TPGNs annealed above $600^{\circ} \mathrm{C}$ for $1 \mathrm{~h}$. Dark regions (indicated by the arrow) appear on the surface of the nanoparticles due to the slow diffusion of gold. (b) SEM image of TPGNs after annealing at $750^{\circ} \mathrm{C}$ for an hour. It looks like a certain layer covers the nanoparticles, hiding its porous structure. Note the grain boundaries appeared on the initially continuous $\mathrm{TiO}_{2}$ layer.

the SEM images, the nanoparticles are overlaid by a layer, which hides the porous structure [see Fig. 2(b)].

Figure 3 shows a TEM BFI image of two particles and the $\mathrm{x}$-ray elemental distribution maps of gold and titanium of the same area. The sample was annealed at $900^{\circ} \mathrm{C}$ for $1 \mathrm{~h}$. As can be clearly seen on the cross section [Fig. 3(a)], the porous gold structure disappeared. It collapsed into a faceted solid gold nanoparticle (SGN) sitting inside a titania shell. The $\mathrm{TiO}_{2}$, which covered the surface of the ligaments initially, assembled into a fragmented, about $50 \mathrm{~nm}$ thick, overlayer [see also Figs. 3(b)-3(d)].

\section{B. Optical properties of the titania-porous gold hybrid nanoparticles}

Extinction spectra were measured in the spectral range of $300-2000 \mathrm{~nm}$. As can be seen in Fig. 4, there are two strong plasmon peaks in this spectra: one in the visible $(\sim 400 \mathrm{~nm})$ and one in the near-infrared region $(\sim 1400 \mathrm{~nm})$. The one with the longer wavelength is called the dipole plasmon peak and the other one (at about $400 \mathrm{~nm}$ ) is called the quadrupole plasmon peak. ${ }^{12}$ Due to the coating, that is, forming TPGNs, the dipole plasmon peak shifts $\sim 350-400 \mathrm{~nm}$, while the quadrupole $\sim 150 \mathrm{~nm}$ to the IR direction. Moreover, $\mathrm{TiO}_{2}$ has a strong absorption at about $300 \mathrm{~nm} ;{ }^{30}$ accordingly, the titania coating provokes a steep increase at the beginning of the spectra.

Annealing the TPGNs at low temperature, lower than $600^{\circ} \mathrm{C}$, the position of the plasmon peaks practically does not change. On the other hand, the annealing of the samples above $600^{\circ} \mathrm{C}$ for 30 min produces a high $(\sim 250 \mathrm{~nm})$ blueshift of the dipole and a redshift of the quadrupole plasmon peaks, respectively. This can be explained by applying the Mie theory for multilayered spheres, ${ }^{31}$ when $\mathrm{TiO}_{2}$ with large refractive index covers a gold nanosphere. An additional $30 \mathrm{~min}$ annealing on the same temperature results in no change in the position of the quadrupole peak, but a slight redshift on the dipole plasmon peak. The reason for this might be a slight increase of the pore size due to the annealing as it was explained by Rao et al. ${ }^{14}$ using Finite-difference Time-Domain (FTDT) simulations. Figures 5(a) and 5(b) show this effect, where the relative changes in plasmon peak position are plotted as a function of the annealing temperature. These figures also display that the position of the plasmon peaks does not change further above $\sim 800^{\circ} \mathrm{C}$.

According to the experienced morphological and optical changes due to the annealing, it is obvious that the change in the optical properties is related to the variation of the morphology of the TPGNs. To check the validity of this assumption, we prepared an artificial core-shell structured specimen with similar morphology to the ones shown in Fig. 3. Porous gold nanoparticles have been fabricated in the same way as we prepared the $\mathrm{Au}-\mathrm{Ag}$ alloy nanoparticles. After dealloying the sample was heated at $500{ }^{\circ} \mathrm{C}$ for $30 \mathrm{~min}$ to form solid gold nanoparticles (SGNs). Figure 6(a) shows the extinction spectra of this sample. As can be seen, the dipole plasmon peak of the SGNs is shifted toward the shorter wavelength (blueshift) more than $300 \mathrm{~nm}$ [see the corresponding black and red curves in Fig. 6(a)]. This blueshift of the dipole resonance peak is due to the heat treatment since while the PGN transforms into SGN, the volume of the nanoparticle is decreased, i.e., a shorter dipole can form upon the optical excitation. The SGNs were then coated with a $50 \mathrm{~nm}$ thick $\mathrm{TiO}_{2}$ layer (TSGNs). The extinction spectra show that the dipole peak shifted $\sim 400 \mathrm{~nm}$ to the red direction (blue curve). The value of the total shift ( $\sim 200 \mathrm{~nm}$ blueshift) is practically the same as in the case of the TPGNs annealed at or above $800^{\circ} \mathrm{C}$, when the core-shell structure formed due to hightemperature annealing. The artificially prepared core-shell particles were annealed at $900^{\circ} \mathrm{C}$ for $30 \mathrm{~min}$ to check its thermal stability. The particles proved to be stable indeed, but grain boundaries appeared in the $\mathrm{TiO}_{2}$ layer [Fig. 6(b)]. Concerning the extinction spectra of the annealed specimen, one can see in Fig. 6(a) that the position of the dipole plasmon peak did not change significantly (green curve). It is proved that the morphological change invokes the change of the extinction spectra of the samples.

From an application point of view, it is important if the resonance frequency of the local plasmon wave could be kept for a certain value after tuning, i.e., the sample should be stable at a lower temperature range for relatively long term. In order to check this, a specimen, which was annealed at $750^{\circ} \mathrm{C}$ for $1 \mathrm{~h}$, was chosen. 

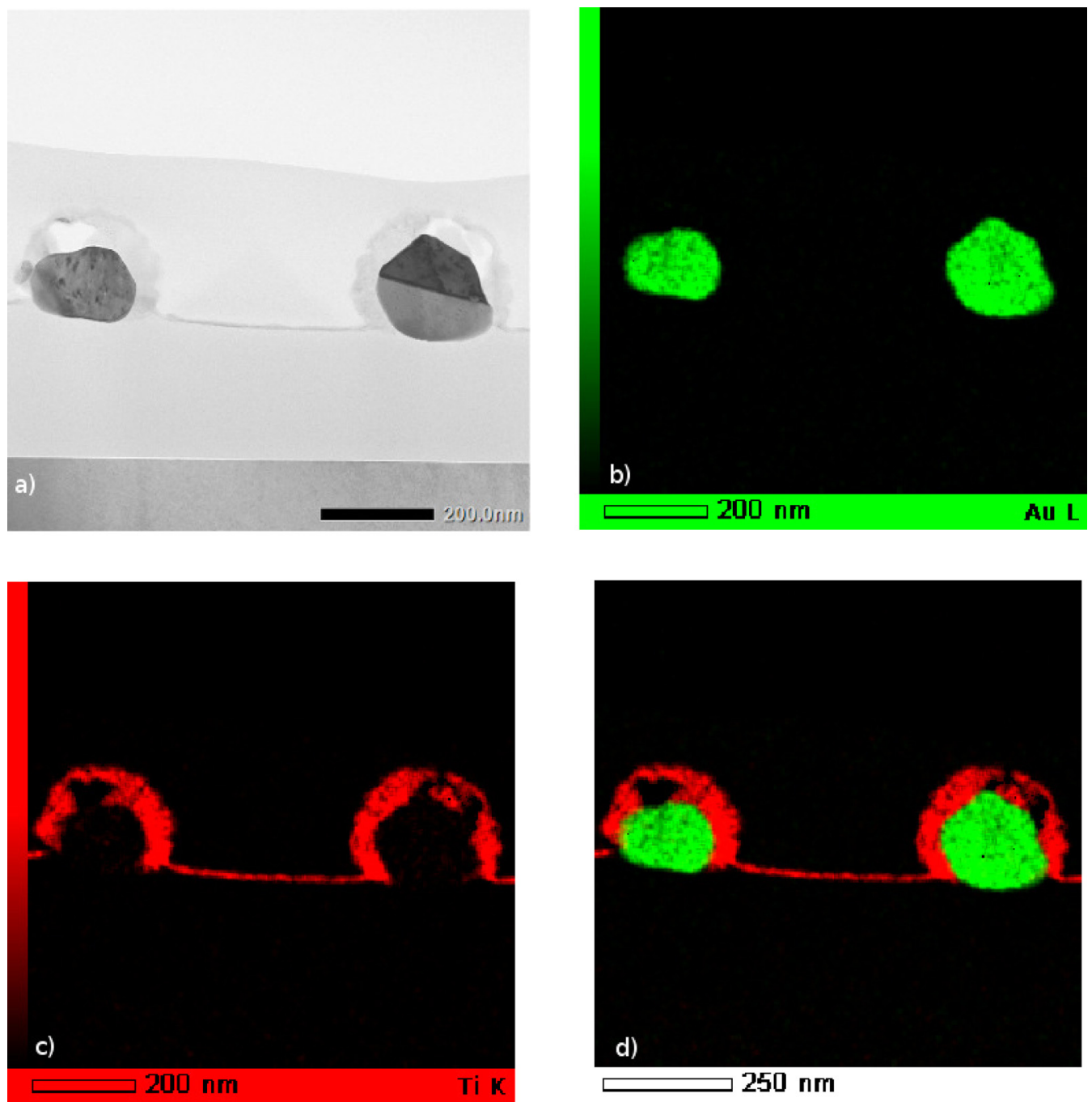

$250 \mathrm{~nm}$

FIG. 3. TPGNs cross cut by FIB and imaged by TEM/EDS after annealing at $900^{\circ} \mathrm{C}$ for an hour in air. The porous structure of the gold collapsed completely into a solid sphere and the oxide initially covering the ligaments $(7 \mathrm{~nm})$ appeared on its surface as a $50 \mathrm{~nm}$ thick layer (compared to Fig. 1). Note that the almost horizontal line inside the Au sphere on the right in figure (a) is a grain-boundary. (a) Cross section view of TPGNs, (b) Au elemental distribution, (c) Ti elemental distribution, and (d) Au and Ti distribution.

With this annealing, the dipole and the quadrupole peaks were tuned to $1400 \mathrm{~nm}$ and $550 \mathrm{~nm}$, respectively. The specimen was then postannealed at $350{ }^{\circ} \mathrm{C}$ for $30 \mathrm{~min}$ and the extinction spectra were measured. The morphology of the TPGNs and the position of these important peaks did not change [see the blue marks in Figs. 5(a) and 5(b)], so this specific optical property can be welltuned and is stable at a lower temperature.

\section{DISCUSSION}

Up to $600{ }^{\circ} \mathrm{C}$, the morphology is unchanged and as a consequence, the optical properties also remain as in the as-prepared state. Annealing the TPGNs above $800^{\circ} \mathrm{C}$, however, the structure changes dramatically; the gold forms a solid spherical particle, which is covered by a titania layer, forming a core-shell structure (see Fig. 3). Accordingly, the optical properties of the TPGNs are significantly different as compared to the as-prepared ones and those annealed up to $600^{\circ} \mathrm{C}$ but do not change further above $800^{\circ} \mathrm{C}$.

In addition to the shifting of the peaks, the changes in their intensity can also be well explained by the Mie theory ${ }^{31,32}$ for multilayered structures. Layering $\mathrm{TiO}_{2}$ on $\mathrm{Au}$ spheres, the thicker the oxide layer, the higher the intensity of the extinction peak for all the plasmon modes. Similarly, increasing the refractive index of the 


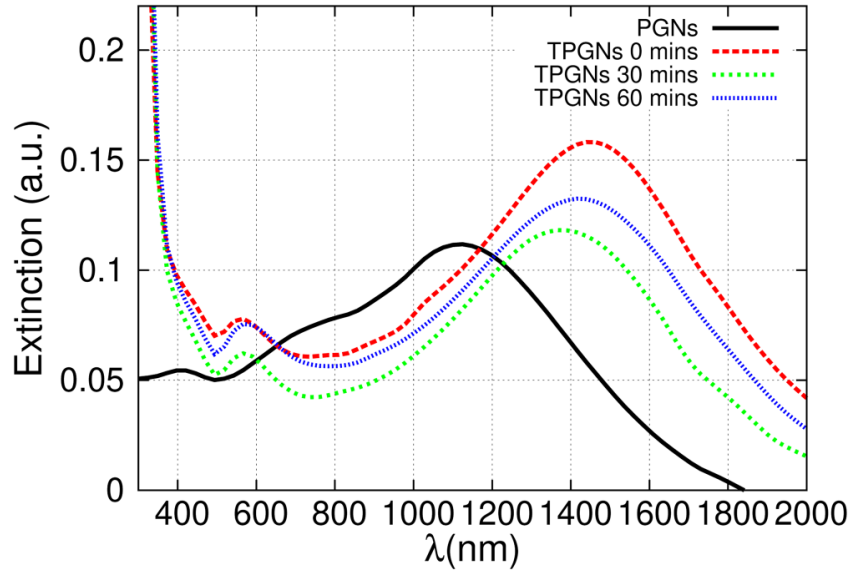

FIG. 4. Optical extinction spectra of the as-prepared PGNs and TPGNs; moreover, the TPGNs annealed at $600^{\circ} \mathrm{C}$ for 30 and $60 \mathrm{~min}$ in air. By comparing the black and red lines, we can see the effect of the coating: the significant redshift of the plasmon peaks. The annealing causes, however, a blueshift of the dipole plasmon peak.

cover layer increases the intensity values. Both are in accordance with the measured spectra: (i) Covering the metallic nanospheres with titania increases the intensity of both the dipole and the quadrupole plasmon peaks. (ii) Annealing the hybrid nanostructures at a low temperature, the amorphous $\mathrm{TiO}_{2}$ transforms to the anatase phase, and as the refractive index of the anatase at a low temperature is almost equal to the amorphous one, ${ }^{33}$ no significant intensity change is expected. Annealing, however, above the anatase/ rutile phase transformation temperature changes the situation significantly, since the refractive index of the rutile is $\sim 10 \%$ higher than that of the other two phases; accordingly, the intensity of the different plasmon modes increases [see Figs. 4 and 6(a)].

We have seen that the extinction spectra of the artificially prepared TSGNs are the same in its main characteristics than the TPGNs annealed at a high temperature. These observations support the idea that the change of the optical properties is related to the variation of the morphology of the TPGNs.

All these suggest that the temperature range can be divided into three regions: the low-temperature state below $600{ }^{\circ} \mathrm{C}$, the transition state from 600 to $800^{\circ} \mathrm{C}$, and the high-temperature state above $800^{\circ} \mathrm{C}$. In the low-temperature state, the hybrid nanostructures are morphologically as well as optically stable. In the transition state, there is a continuous transition of the morphology accompanied by a continuous shift of the dipole and quadrupole plasmon peaks. In the high-temperature state the core-shell structure forms: Au core with $\mathrm{TiO}_{2}$ shell.

The experiments showed that during annealing of the TPGNs above $600{ }^{\circ} \mathrm{C}$, the titania starts to go to the outer surface of the particles. The melting point of titania is $1846^{\circ} \mathrm{C}$, which is about two times of the maximum annealing temperature we used. It is, therefore, obvious that the solid-state diffusion is not fast enough to cover the transport of titania in such a large amount. There is, however, another effect that may play an important role. It is well known that the melting temperature of gold gets lower with decreasing nanoparticle size. The ligament thickness in the porous gold nanoparticles is about $7-10 \mathrm{~nm}$. According to literature data, ${ }^{34-36}$ for this size, the corresponding melting point of $\mathrm{Au}$ is only about $100^{\circ} \mathrm{C}$ higher than the maximal annealing temperature used in this study. Moreover, the surface diffusivity of Au gets very high $\left(10^{-9} \mathrm{~m}^{2} / \mathrm{s}\right) .{ }^{36} \mathrm{In}$ addition, around $700^{\circ} \mathrm{C}, \mathrm{TiO}_{2}$ transforms from the anatase to the rutile phase. We also confirmed this phase transformation by electron diffraction using transmission electron microscopy; the $\mathrm{TiO}_{2}$ shell on the Au core formed due to annealing at or above $800^{\circ} \mathrm{C}$ was proved to be rutile.
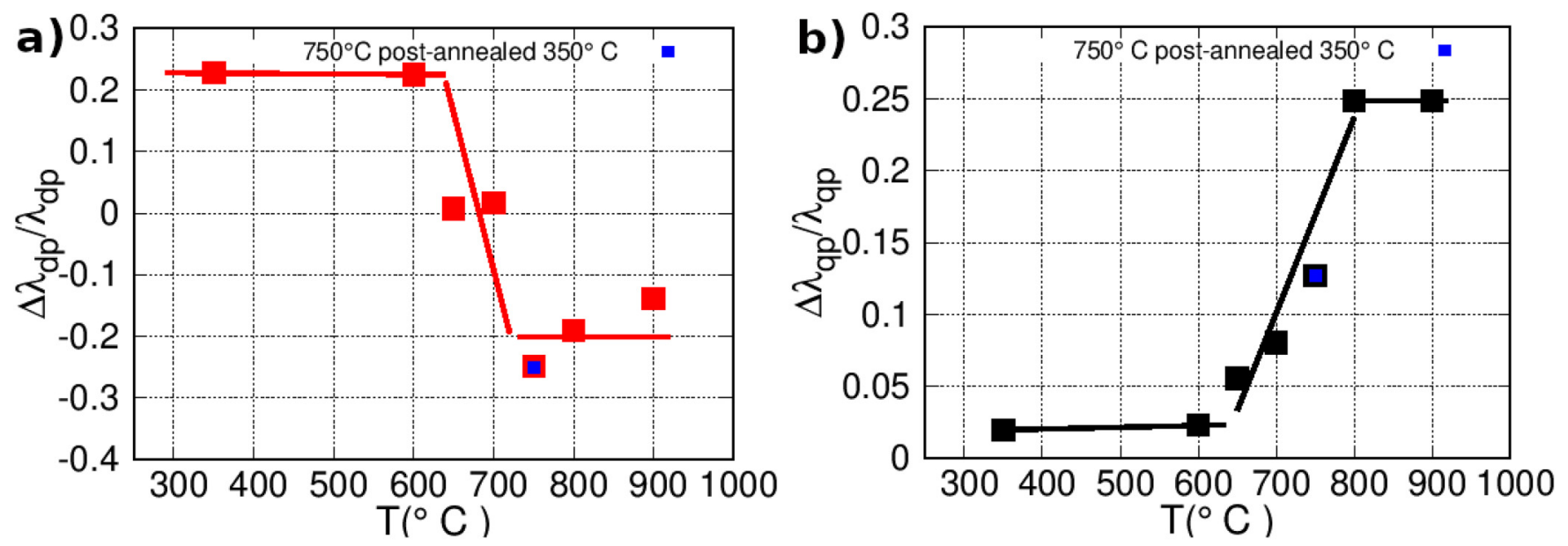

FIG. 5. (a) TPGN's relative dipole plasmon peak position as a function of annealing temperature ( $1 \mathrm{~h}$ annealing time). (b) Relative quadrupole plasmon peak position of TPGNs is plotted against the annealing temperature (1 $\mathrm{h}$ annealing time). 

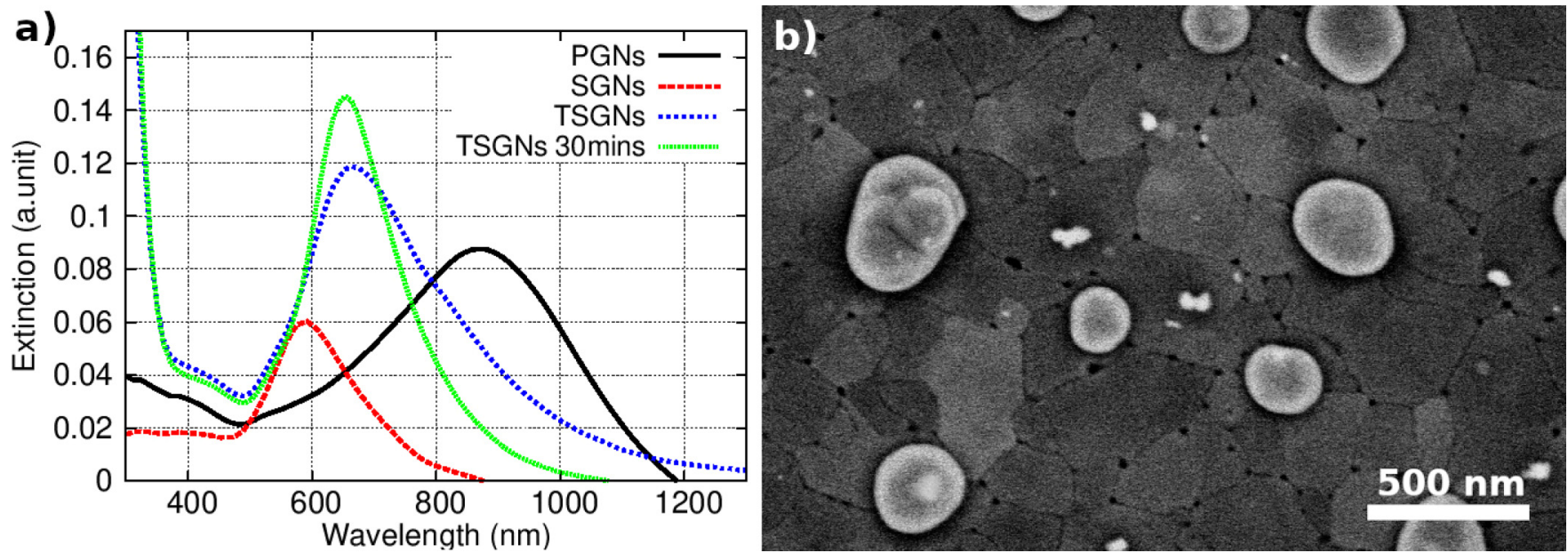

FIG. 6. (a) Optical extinction spectra of porous gold nanoparticles (PGNs), solid gold nanoparticles (SGNs), titania coated solid gold nanoparticles (TSGNs), and $900{ }^{\circ} \mathrm{C}$ $30 \mathrm{~min}$ in air annealed TSGNs. (b) SEM image of artificial TSGNs after annealing at $900^{\circ} \mathrm{C}$ for an hour in air. It is clearly seen that the initial continuous titania layer is also fragmented and covers SGNs.

Accordingly, the following scenario can be imagined on the transformation, which takes place between the low and hightemperature states. Close to the melted state of gold, thanks to its high surface diffusivity, the gold atoms diffuse inward, forming a nano-sphere, pushing the rutile flakes-which evolve due to the allotropic phase transformation-outward, to the surface of the gold particle. The driving force for this process presumably is to reduce the total $\mathrm{TiO}_{2} / \mathrm{Au}$ interface as much as possible. The key is that this process can only start after the titania coating layer starts to transform to the rutile phase.

Only one similar study can be found in the literature investigating the morphology of metal oxide-coated PGNs. ${ }^{14}$ This is the alumina coated PGN (APGN) also mentioned in the introduction. There, the authors' primary goal was to show that the aluminum oxide coating can passivate the structure up to a high temperature. No shift in the plasmon resonance wavelength was observed up to about $600^{\circ} \mathrm{C}$. Then, raising the temperature to $1000^{\circ} \mathrm{C}$, the visible-range plasmon resonance wavelength shifted $\sim 30 \mathrm{~nm}$ in the red direction. This represents a relative shift of $\sim 5 \%$.

In our case, however, the relative shift of the visible-range plasmon resonance wavelength is $\sim 25 \%$, while that in the nearinfrared range is $\sim 40 \%$, which is at least five times that observed for APGN. This huge range of tunability is due to the fact that while a mere morphological change occurred in APGNs (which is different from that observed in TPGN), in TPGNs, the refractive index of the dielectric surrounding the PGNs also changes during heat treatment due to the anatase-rutile phase transformation. Thus, in the case of TPGNs, we can speak of not only morphological but also in situ local refractive index change induced tuning (ILRICIT).

ILRICIT can work on all coatings where a change in temperature is accompanied by a change in refractive index-e.g., due to the phase transformation.

\section{CONCLUSIONS}

We conclude that coating the PGNs by titania changes their optical properties, but preserves their morphology up to $\sim 600^{\circ} \mathrm{C}$. Annealing above $\sim 600^{\circ} \mathrm{C}$, the morphology of the TPGNs starts to transform; a fast surface diffusion of gold and the allotropic phase transformation of $\mathrm{TiO}_{2}$ begin to take place. Above $\sim 800^{\circ} \mathrm{C}$, there is no change in the morphology, after a core-shell structure rapidly formed.

Concerning the optical properties, unlike the alumina, annealing the TPGNs above $600^{\circ} \mathrm{C}$ but below $800^{\circ} \mathrm{C}$, remarkable blueshift and redshift take place in the position of the dipole and quadrupole plasmon peaks, respectively. Above $\sim 800^{\circ} \mathrm{C}$, there is no change in the optical properties.

As was seen, the optical properties of porous gold nanoparticles can be well tuned in a wide range of wavelengths by applying titania coating followed by annealing. The displacement of the dipole and quadruple peaks can be well adjusted using proper annealing conditions. The set frequency of TPGNs does not change after tuning; its value is not changed even by low temperature (below the phase transformation) heat treatment. The favorable tunability is twofold: not only the change of the morphology but also the in situ change in the local refractive index contributes to the plasmon resonance wavelength shift. This provides a unique possibility for continuous tuning of the resonance frequencies of the TPGNs and advertises that this hybrid structure might be a potential candidate for optical applications.

\section{AUTHORS' CONTRIBUTIONS}

C.C. and Z.E. headed the research. L.J., B.P., S.S., and C.C. designed and carried out most of the experiments. M.K. and K.F. carried out FIB preparation as well as STEM + EDS measurements. 
C.C., L.J., and Z.E. wrote the manuscript, and all authors discussed the results and contributed to revisions.

\section{ACKNOWLEDGMENTS}

The research was financed by the Higher Education Institutional Excellence Programme (No. NKFIH-1150-6/2019) of the Ministry of Innovation and Technology in Hungary, within the framework of the Energetics thematic programme of the University of Debrecen. A part of the experimental infrastructure used in this work was supported by the GINOP (No. 2.3.2-15-2016-00041) in Hungary. The authors are grateful to Dr. István Csarnovics for his help in the optical measurements.

\section{REFERENCES}

'Y. Sun, B. Mayers, and Y. Xia, "Template-engaged replacement reaction: A QNE-step approach to the large-scale synthesis of metal nanostructures with hollow interiors," Nano Lett. 2, 481-485 (2002).

${ }^{2}$ Y. Sun, B. Mayers, and Y. Xia, "Metal nanostructures with hollow interiors," Adv. Mater. 15, 641-646 (2003).

${ }^{3}$ Y. Yin, R. Rioux, C. Erdonmez, S. Hughes, G. Somorjai, and A. Alivisatos, "Formation of hollow nanocrystals trough the nanoscale Kirkendall effect," Science 304, 711-714 (2004).

${ }^{4}$ Y. Yin, C. Erdonmez, A. Cabot, S. Hughes, and A. Alivisatos, "Colloidal synthesis of hollow cobalt sulfide nanocrystals," Adv. Funct. Mater. 16, 1389-1399 (2006).

${ }^{5}$ H. Fan, M. Knez, R. Scholtz, D. Hesse, K. Nirelsch, M. Zacharias, and U. Gösele, "Influence of surface diffusion on the formation of hollow nanostructures induced by the Kirkendall effect: The basic concept," Nano Lett. 7, 993-997 (2007).

${ }^{6}$ A. Chen, S. Shi, Y. Qiu, X. Xie, H. Ruan, J. Gu, and D. Pan, "Pore-size tuning and optical performances of nanoporous gold films," Micropor. Mesopor. Mater. 202, 50-56 (2015).

${ }^{7}$ M. Shao, K. Shoemaker, A. Peles, K. Kaneko, and L. Protsailo, "Pt monolayer on porous $\mathrm{Pd}-\mathrm{Cu}$ alloys as oxygen reduction electrocatalysts," J. Am. Chem. Soc. 132, 9253-9255 (2010).

${ }^{8}$ A. Hodge, J. Hayes, J. Caro, J. Biener, and A. Hamza, "Characterization and mechanical behavior of nanoporous gold," Adv. Eng. Mater. 8, 853-857 (2006).

${ }^{9} \mathrm{G}$. Glodán, C. Cserháti, I. Beszeda, and D. L. Beke, "Production of hollow hemisphere shells by pure Kirkendall porosity formation in $\mathrm{Au} / \mathrm{Ag}$ system," Appl. Phys. Lett. 97, 113109-113112 (2010).

${ }^{10} \mathrm{G}$. Glodán, C. Cserháti, and D. L. Beke, "Temperature-dependent formation and shrinkage of hollow shells in hemispherical Ag/Pd nanoparticles," Philos. Mag. 92, 3806-3812 (2012).

${ }^{11}$ R. Nakamura, D. Tokozakura, H. Nakajima, J. Lee, and H. Mori, "Hollow oxide formation by oxidation of $\mathrm{Al}$ and $\mathrm{Cu}$ nanoparticles," J. Appl. Phys. 101, 074303 (2007).

${ }^{12}$ A. Kosinova, D. Wang, P. Schaaf, O. Kovalenko, L. Klinger, and E. Rabkin, "Fabrication of hollow gold nanoparticles by dewetting, dealloying and coarsening," Acta Mater. 102, 108-115 (2016).

${ }^{13}$ A. Kosinova, D. Wang, E. Baradács, B. Parditka, T. Kups, L. Klinger, Z. Erdélyi, P. Schaaf, and E. Rabkin, "Tuning the nanoscale morphology and optical properties of porous gold nanoparticles by surface passivation and annealing," Acta Mater. 127, 108-116 (2017).

${ }^{14}$ W. Rao, D. Wang, T. Kups, E. Baradács, B. Parditka, Z. Erdélyi, and P. Schaaf, "Nanoporous gold nanoparticles and $\mathrm{Au} / \mathrm{Al}_{2} \mathrm{O}_{3}$ hybrid and nanoparticles with large tunability of plasmonic properties," ACS Appl. Mater. Interfaces 9, 6273-6281 (2017).

${ }^{15}$ M. Zayats, "Nonlinear plasmonics," Nat. Photon. 6, 737-748 (2012).
${ }^{16} \mathrm{M}$. Brongersma, N. Halas, and P. Nordlander, "Plasmon-induced hot carrier science and technology," Nat. Nanotechnol. 10, 25-34 (2015).

${ }^{17}$ M. Paul, "Surface plasmon spectroscopy of nanosized metal particles," Langmuir 12, 788-800 (1996).

${ }^{18}$ K. Kelly, E. Coronado, L. Zhao, and G. Schatz, "The optical properties of metal nanoparticles: The influence of size, shape, and dielectric environment," J. Phys. Chem. B 107, 668-677 (2003).

${ }^{19} \mathrm{P}$. Jain, K. Lee, I. El-Sayed, and M. El-Sayed, "Calculated absorption and scattering properties of gold nanoparticles of different size, shape, and composition: Applications in biological imaging and biomedicine," J. Phys. Chem. B 110, 7238-7248 (2006).

${ }^{20}$ C. Haynes, R. V. Duyne, and A. Nanosphere Lithography, "Versatile nanofabrication tool for studies of size-dependent nanoparticle optics," J. Phys. Chem. B 105, 5599-5611 (2001).

${ }^{21}$ S. Boriskina, T. Cooper, L. Zeng, G. Ni, J. Tong, Y. Tsurimaki, Y. Huang, L. Meroueh, G. Mahan, and G. Chen, "Losses in plasmonics: From mitigating energy dissipation to embracing loss-enabled functionalities," Adv. Opt. Photon. 9, 775-827 (2017).

${ }^{\mathbf{2 2}} \mathrm{Y}$. Shen, "Surface properties probed by second-harmonic generation and sumfrequency generation," Nature 337, 519-525 (1989).

${ }^{23}$ R. Boyd, Nonlinear Optics, 3rd ed. (Academic Press, 2008).

${ }^{24}$ A. Hermans, C. Kieninger, K. Koskinen, A. Wickberg, E. Solano, J. Dendooven, M. Kauranen, S. Clemmen, M. Wegener, C. Koos, and R. Baets, "On the determination of $\chi^{(2)}$ in thin films: A comparison of one-beam second-harmonic generation measurement methodologies," Sci. Rep. 7, 44581 (2017).

${ }^{25}$ M. Taghinejad, Z. Xu, K.-T. Lee, T. Lian, and W. Cai, “Transient second-order nonlinear media: Breaking the spatial symmetry in the time domain via hot-electron transfer," Phys. Rev. Lett. 124, 013901 (2020).

${ }^{\mathbf{2 6}} \mathrm{B}$. Lambrecht, A. Leitner, and F. Aussenegg, "Femtosecond decay-time measurement of electron- plasma oscillation in nanolithographically designed silver particles," Appl. Phys. B 64, 269-272 (1997).

${ }^{27}$ B. Lambrecht, A. Leitner, and F. Aussenegg, "SHG studies of plasmon dephasing in nanoparticles," Appl. Phys. B 68, 419-423 (1999).

${ }^{28}$ R. Antoine, P. Brevet, H. Girault, D. Bethell, and D. Schiffrin, "Surface plasmon enhanced non-linear optical response of gold nanoparticles at the air/ toluene interface," Chem. Commun. 19, 1901-1902 (1997).

${ }^{29}$ R. Antoine, M. Pellarin, B. Palpant, M. Broyer, B. Pre'vel, A. Perez, P. Galetto, P. Brevet, and H. Girault, "Surface plasmon enhanced second harmonic response from gold clusters embedded in an alumina matrix," J. Appl. Phys. 84, 4532-4536 (1998).

${ }^{30}$ J. Wu, G. Yue, J. L. Y. Xiao, M. Huang, Q. T. Z. Lan, Y. Huang, L. Fan, S. Yin, and T. Sato, "An ultraviolet responsive hybrid solar cell based on titania/poly (3-hexylthiophene)," Sci. Rep. 3, 1283 (2013).

${ }^{31}$ K. Ladutenko, U. Pal, A. Rivera, and O. Peña-Rodríguez, "Mie calculation of electromagnetic near-field for a multilayered sphere," Comput. Phys. Commun. 214, 225-230 (2017).

${ }^{32}$ D. Sarid and W. Challener, Modern Introduction to Surface Plasmons: Theory, Mathematica Modeling, and Applications (Cambridge University Press, 2010), pp. 201-255.

${ }^{33} \mathrm{~A}$. Bendavid and P. Martin, "Review of thin film materials deposition by the filtered cathodic vacuum arc process at CSIRO," J. Aust. Ceram. Soc. 50, 86-101 (2014).

${ }^{34} \mathrm{P}$. Buffat and J. Borel, "Size effect on the melting temperature of gold particles," Phys. Rev. A 13, 2287-2298 (1976).

${ }^{35} \mathrm{Q}$. Jiang, S. Zhang, and M. Zhao, "Size-dependent melting point of noble metals," Mater. Chem. Phys. 82, 225-227 (2003).

${ }^{36}$ W. Zhang, Y. Liu, D. Zhou, J. Wen, L. Zheng, W. Liang, and F. Yang, "Diffusion kinetics of gold in $\mathrm{TiO}_{2}$ nanotube arrays for formation of $\mathrm{Au} @ \mathrm{TiO}_{2}$ nanotube arrays, RSC Adv. 6, 48580-48588 (2016). 